\title{
O ensino da língua tukano que não fala
}

\author{
Silvio Sanches Barreto ${ }^{1}$
}

\begin{abstract}
Resumo
Este texto convida a reflexionar sobre o ensino da língua materna para a criança indígena enquanto ser em formação pertencente a uma etnia. O objetivo foi de analisar o processo histórico do funcionamento e a pedagogia de ensino no município de Manaus. $O$ referencial teórico desta pesquisa foi embasado no teor dos direitos indígenas e direitos fundamentais segundo a Constituição Brasileira de 1988, no que se refere ao artigo 231. O conjunto da legislação nacional dispõe a respeito do direito dos povos indígenas a uma educação diferenciada, para que os povos originários mantenham sua cultura viva, de forma articulada e planejada com órgãos governamentais das três esferas de governos. Quanto à metodologia, foi adotada uma abordagem qualitativa com pesquisa de campo, utilizando questionário fechado e entrevista semiestruturada. Os resultados apontam que os Centros Municipais funcionam de modo irregular, mas precisa-se ser revisto o ensino da língua tukano para não continuar o ensino da língua materna que não fala. Quando chega certa idade, tem vergonha e chegou uma conclusão aproximada ou equivocada de que somente os adultos que valorizam sua cultura, mesmo estando longe das aldeias e fora de suas origens, mantém a cultura viva, mesmo no contexto urbano. Uma situação preocupante para a próxima geração urbana, uma geração de ouvintes, mesmo sendo filhos dos próprios falantes. A língua é um dos elementos culturais para afirmação de identidade, para a unidade social.
\end{abstract}

Palavras-Chaves: Saberes; Língua, Fortalecimento; Psicopedagogia.

\section{Resumen}

Este texto invita a reflexionar sobre la enseñanza de la lengua materna al niño indígena mientras se encuentra en educación perteneciente a un grupo étnico. El objetivo fue analizar el proceso histórico de operación y pedagogía docente en el municipio de Manaus. El marco teórico de esta investigación se basó en el contenido de los derechos indígenas y los derechos fundamentales de acuerdo con la Constitución brasileña de 1988, con respecto al artículo 231. El conjunto de leyes nacionales sobre el derecho de los pueblos indígenas a la educación diferenciada, de modo que los pueblos nativos mantienen viva su cultura, de manera articulada y planificada con las agencias gubernamentales de las tres esferas del gobierno. En cuanto a la metodología, se adoptó un enfoque cualitativo con investigación de campo, utilizando un cuestionario cerrado y una entrevista semiestructurada. Los resultados muestran que los Centros Municipales

\footnotetext{
${ }^{1}$ Pertencente do povo indígena Bará do Grupo Tukano Oriental, noroeste amazônico, Estado do Amazonas. Graduado em Filosofia pela Faculdade Salesiana Dom Bosco-FSDB/Manaus (2014); Especialização em Gestão Escolar pela Faculdade Educacional da Lapa - FAEL/Paraná (2019); Mestre em Antropologia Social pela Universidade Federal do Amazonas-UFAM (2019) e Doutorando da mesma. Membro do Núcleo de Estudos da Amazônia/NEAI-UFAM, Membro do Colegiado Indígena/PPGAS/UFAM; Bolsista da CAPES.
} 
funcionan de manera irregular, pero la enseñanza del idioma tukano necesita ser revisada para no continuar enseñando la lengua materna que no habla. Cuando llega una cierta edad, se avergüenza y llega a una conclusión aproximada o errónea de que solo los adultos que valoran su cultura, aunque estén lejos de las aldeas y fuera de sus orígenes, mantienen la cultura viva, incluso en el contexto urbano. Una situación preocupante para la próxima generación urbana, una generación de oyentes, a pesar de que son hijos de los mismos hablantes. El lenguaje es uno de los elementos culturales para afirmar la identidad, para la unidad social.

Palabras clave: Saberes; Lengua, Fortalecimiento; Psicopedagogía.

\section{Introdução}

O ensino da língua materna que não fala de Centros Municipais da Educação Escolar Indígena do Município de Manaus, Estado do Amazonas. O aluno indígena aprende nos Centros Municipais a sua língua materna por meio de projeto pedagógico para o fortalecimento cultural.

Primeiro é um recorte histórico de Educação Escolar Indígena, a nível nacional. O Estado Brasileiro reconhece aos índios sua organização social, costumes, línguas, crenças e tradições, e o direitos originários sobre as terras que tradicionalmente ocupam, competindo à União demarca-las, proteger e fazer respeitar todos os seus bens (Art. 231).

Segundo, quanto à metodologia de pesquisa, se deu sob a abordagem qualitativa por meio de pesquisa documental e de campo, no que se refere à coleta de dados, essa se realizou por meio da pesquisa in loco. Ainda, nesta parte foram empregados os seguintes instrumentos: a observação participante, questionário com perguntas fechadas e entrevistas individuais semiestruturadas, o registro dos relatos de memória.

Terceiro, o ensino da língua tukano de Centros Municipais da Educação Escolar Indígena do Povo Indígena Tukano, noroeste amazônico. Nesta seção é analisar e discutir as falas das lideranças e das professoras bilíngues sobre ensino da língua materna, a língua tukano de Centros Culturais de duas comunidades do Alto Rio Negro: Numiâ Kura da AMARN e da Comunidade Bayaroá.

O resultado esperado de pesquisa de alunos indígenas de Centros Municipais. Enfim, considerações finais, o ensino da língua materna tukano que não fala para fortalecimento cultural indígena do Alto Rio Negro na cidade de Manaus.

\section{A Escrita que não fala}

Vou contar a história que deu o título deste trabalho, quando estava elaborando o projeto de pesquisa para a conclusão do curso de especialização em Gestão Escolar. Naquele momento de definição para a pesquisa, para mim tornou-se um começo de 
conversa sem meio e sem fim. A professora Rosiane ${ }^{2}$ me contou esta história de sua avó materna, a história de Dona Quitéria Pena.

A Dona Quitéria, quando ela estava viva ainda, este fato ocorreu em Pari Cachoeira, na Cabeça do Cachorro, noroeste amazônico. Todo domingo tinha oratório, uma atividade recreativa dos missionários salesianos, de jogos e das brincadeiras, uma das atividades dos padres salesianos de alfabetizar as pessoas já adultas, e Dona Quitéria estava lá no meio garotadas aprendendo a escrever.

Um belo dia de domingo, a Dona Quitéria não entregou mais atividade de alfabetização. Então, ela trouxe uma tarefa para casa, e passaram-se os dias da semana e o dia de domingo estava aproximando-se para correção. No entanto, a Dona Quitéria resolveu fazer tarefa sozinha. Para tanto, ela pediu para fazer uma leitura para seu filho, dizendo:

- Não sei se minha escrita fala.

O seu filho era professor da escolinha rural, daquele tempo, ele pegou o caderno, e disse para a sua mãe:

- Mãe, a sua escrita não fala! Ouvindo a resposta do filho, a Dona Quitéria ficou muito triste e nunca mais foi para alfabetização. E daí que surgiu a ideia do título deste trabalho, $O$ ensino da língua materna que não fala, ou melhor, o ensino da língua tukano que não fala.

\section{Recorte histórico de política educacional à educação escolar indígena}

Historicamente, os povos indígenas sempre conquistaram os seus direitos por meio de lutas e de reivindicações que são garantidos pela Constituição Brasileira de 1988, no que se refere artigo 231 que São reconhecidos aos índios sua organização social, costumes, línguas, crenças e tradições, e o direitos originários sobre as terras que tradicionalmente ocupam, competindo à União demarca-las, proteger e fazer respeitar todos os seus bens.

Os povos originários do Brasil vão à luta pelos seus direitos indígenas constitucionais. No caso aqui, a educação escolar indígena, uma escola indígena para manter os processos de aprendizagens próprios, criando e recriando continuamente sua história, seus valores, seus projetos de vida, e, nas últimas décadas, o movimento indígena tem se articulado muito, enquanto instrumento de mobilização para as conquistas. Mas também encontramos em outro artigo 210 \& $2^{\circ} \ldots$ assegurada às comunidades indígenas também a utilização de suas línguas maternas e processos próprios de aprendizagem. Então, no Congresso Brasileiro de Qualidade na Educação: Formação de Professores. A Educação Escolar Indígena, Luis Donizete (2002), menciona, no Painel 5 - Legislação Escolar Indígena:

\footnotetext{
${ }^{2}$ A professora Rosiane é minha digníssima esposa e neta da Dona Quitéria. 70
} 
A Constituição de 1988, assegurou-se aos índios no Brasil o direito de permanecerem índios, isto é, de permanecerem eles mesmos com suas línguas, culturas e tradições. Ao reconhecer que os índios poderiam utilizar as suas línguas maternas e os seus processos de aprendizagem na educação escolar, instituiu-se a possibilidade de a escola indígena contribuir para o processo de afirmação étnica e cultural desses povos e ser um dos principais veículos de assimilação e integração (Grupioni, 2002, p.130).

Todo este processo, o poder municipal de Manaus avançou na definição do decreto, aprovação das diretrizes, plano de cargos e carreira da categoria de professores indígenas e, regularização de Centros Municipais, ainda estão em discussão, nem por isso está parado pelo poder público municipal.

Educação Indígena na Lei de Diretrizes e Bases da Educação Nacional (Lei no 9.394) e o Plano Nacional de Educação, têm abordado o direito dos povos indígenas a uma educação diferenciada, pautada pelo uso das línguas indígenas, pela valorização dos conhecimentos e saberes milenares desses povos e pela formação dos próprios índios para atuarem como docentes em suas comunidades (Grupioni, 2002, p.132).

As reivindicações dos movimentos indígenas, sejam a nível nacional e local, sempre demonstram interesse coletivo. Os povos indígenas sempre tiveram objetivos para fortalecer cultural, isso garante no artigo 78 da Lei no 9.394/96 I - Proporcionar aos índios, suas comunidades e povos, a recuperação de suas memorias históricas; a reafirmação de suas identidades étnicas; a valorização de suas línguas e ciências. Escola como lugar de conhecimentos necessários para transitar na sociedade envolvente e os conhecimentos tradicionais de cada povo. Também no artigo 79 da Lei no 9.394/96 I fortalecer as práticas sócio-culturais e a língua materna de cada comunidade indígena. Essa escola é para contribuir com o fortalecimento da identidade étnica e construção de respeito pelas diferenças culturais, como menciona na Referencial Curricular Nacional para as Escolas Indígenas:

Os princípios contidos nas leis dão abertura para a construção de uma nova escola, que respeite o desejo dos povos indígenas de uma educação que valorize suas práticas culturais e lhes dê acesso a conhecimentos e práticas de outros grupos e sociedades. Uma normatização excessiva ou muito detalhada pode, ao invés de abrir caminhos, inibir o surgimento de novas e importantes práticas pedagógicas e falhar no atendimento a demandas particulares colocadas por esses povos. A proposta da escola indígena diferenciada representa, sem dúvida alguma, uma grande novidade no sistema educacional do país, exigindo das instituições e órgãos responsáveis a definição de novas dinâmicas, concepções e 
mecanismos, tanto para que essas escolas sejam de fato incorporadas e beneficiadas por sua inclusão no sistema, quanto respeitadas em suas particularidades (RCNEI: 34).

Os conhecimentos tradicionais se encontram na literatura cultural dos antepassados. As pessoas contam as histórias de seus antepassados, narrando o modo de vida, mas, quando contam as histórias passadas para serem revividas e rememoradas, pois não são simples contos narrados ou memórias, são histórias verdadeiras (Eliade, 1972), que dão ao novo re-significado os valores culturais de seus antepassados, conforme o contexto social e para não serem esquecidos pela nova geração.

A Educação Indígena na Lei de Diretrizes e Bases da Educação Nacional (Lei no 9.394)

A LDB menciona, de forma explícita, a educação escolar para os povos indígenas, no artigo 32, estabelecendo que seu ensino será ministrado em Língua Portuguesa, mas assegura às comunidades indígenas a utilização de suas línguas maternas e processos próprios de aprendizagem. Ou seja, reproduz-se aqui o direito inscrito no artigo 210 da Constituição Federal.

À Educação Escolar Indígena está nos artigos 78 e 79 do Ato das Disposições Gerais e Transitórias da Constituição de 1988. Ali se preconiza como

dever do Estado o oferecimento uma educação escolar bilíngue e intercultural que fortaleça as práticas socioculturais e a língua materna de cada comunidade indígena e proporcione a oportunidade de recuperar suas memórias históricas e reafirmar suas identidades, dando lhes, também, acesso aos conhecimentos técnico científicos da sociedade nacional.

Os dispositivos da LDB possibilitam colocar em prática esses direitos, dando liberdade para cada escola indígena definir, de acordo com suas particularidades, seu respectivo projeto político-pedagógico. Assim, por exemplo, o artigo 23 da LDB trata da diversidade de possibilidades na organização escolar, permitindo o uso de séries anuais, períodos semestrais, ciclos, alternância regular de períodos de estudo, grupos nãoseriados ou por critério de idade, competência ou outros critérios.

\section{A Educação indígena no Plano Nacional de Educação (Lei no 10.172)}

Em 9 de janeiro de 2001, foi promulgado o Plano Nacional de Educação, também conhecido pela sigla PNE, que apresenta um capítulo sobre a Educação Escolar Indígena, 
dividido em três partes. Na primeira parte, faz-se um rápido diagnóstico de como tem ocorrido à oferta da educação escolar aos povos indígenas. Na segunda, apresentam-se as diretrizes para a Educação Escolar Indígena. E na terceira, estão os objetivos e metas que deverão ser atingidos a curto e em longo prazo.

Entre os objetivos e as metas previstos no Plano Nacional de Educação, destacase a universalização da oferta de programas educacionais povos indígenas para todas as séries do Ensino Fundamental, assegurando autonomia para as escolas indígenas, tanto no que se refere ao projeto pedagógico, quanto ao uso dos recursos financeiros, e garantindo a participação das comunidades indígenas nas decisões relativas ao funcionamento dessas escolas. Para que isso se realize, o plano estabelece a necessidade de criação da categoria "escola indígena" para assegurar a especificidade do modelo de educação intercultural e bilíngue e sua regularização nos sistemas de ensino.

\section{Parecer no 14/99 do Conselho Nacional de Educação}

O parecer apresenta a fundamentação da Educação Indígena, determina a estrutura e funcionamento da escola indígena e propõe ações concretas em prol da Educação Escolar Indígena. Merecem destaque, no parecer que institui as diretrizes, a proposição da categoria "escola indígena", a definição de competências para a oferta da Educação Escolar Indígena, a formação do professor indígena, o currículo da escola e sua flexibilização. Essas questões encontraram normatização na Resolução no 3/99, gerada no âmbito das mesmas discussões que ensejaram este parecer.

O conjunto da legislação nacional, a respeito do direito dos povos indígenas a uma educação diferenciada, como visto anteriormente, está estruturado a partir de duas vertentes, que necessariamente precisam convergir, para que esse direito se materialize: de um lado, trata-se de propiciar acesso aos conhecimentos ditos universais e, de outro, de ensejar práticas escolares que permitam o respeito e a sistematização de saberes e conhecimentos tradicionais. É da junção dessas duas vertentes que deve emergir a tão propagada escola indígena.

O município de Manaus cria uma política pública por meio de Decreto Municipal no 1.394/2011 que reconhece as escolas indígenas. Nesse decreto municipal está definida a criação da categoria escola indígena, no âmbito municipal de Manaus da educação básica ${ }^{3}$.

A estrutura e o funcionamento das escolas indígenas são reconhecidos como escola diferenciada, com normas e ordenamento jurídico próprios e diretrizes curriculares do ensino intercultural e

\footnotetext{
${ }^{3}$ Os municípios são atribuídos de oferecer a educação infantil e, com prioridade, o ensino fundamental (LBDBEM/1996, art.11). 
bilíngue, visando à valorização plena das culturas e comunidades dos povos indígenas, à afirmação e à manutenção de suas diversidades étnicas (Parágrafo único, art. 10).

As comunidades indígenas de Manaus fizeram todo este processo de solicitação da escola indígena para suas comunidades no processo de fortalecimento cultural $\left(\operatorname{art.} 2^{\circ}\right)$, pois houve uma discussão a respeito de escola indígena, uma escola diferenciada. A criação da escola indígena em Manaus se deu por conta do Decreto de 2011, no art. $4^{\circ}$ com seguintes objetivos:

Desenvolver a criança (...) na vida de sua comunidade e de seu povo (I, art. $\left.4^{\circ}\right)$;

Formar cidadão para assumir seu papel de interação na sociedade brasileira (II, art. 40);

Consolidar de "projetos societários dos povos e comunidades indígenas" (III, art. 40) art. $\left.4^{\circ}\right)$.

Concretizar os "projetos de autonomia das escolas indígenas" (IV,

Os princípios de organização e funcionamento das escolas indígenas em Manaus, conforme no art. $3^{\circ}$ :

I-Reconhecimento e respeito à diversidade étnica, cultural e linguística dos povos e comunidades indígenas;

I. Valorização dos conhecimentos e saberes tradicionais;

II. Valorização e fortalecimento das culturas indígenas;

III. Diversidade de concepções de ensino e de aprendizagem;

IV. Gestão participante

Segundo, este Decreto Municipal, as escolas indígenas em Manaus deverão ter a terra regularizada para fortalecimento cultual, no que se refere no artigo (art. $5^{\circ}$ ), isto é, reafirmando do artigo 231 da constituição. Em consonância à Lei de Diretrizes e Bases da Educação (LDB) de 1996, no artigo 78 para oferta de educação escolar bilíngue e intercultural aos povos indígenas, ...

Não só basta de ter oferta, mas precisa ter a "organização própria, autônoma, específica e diferenciada" (I, art. 60); assim como suas concepções e "planejamento" devem se basear "nas aspirações de cada comunidade e povo indígena" (II, art. 60), como propõe $\mathrm{V}$. elaboração e produção de material didático-pedagógico, de acordo com os conhecimentos socioculturais e linguísticos de cada povo e ou comunidade indígena.

No capítulo II, Da organização, estrutura e funcionamento das escolas indígenas, conforme III, art. 50, a adoção do ensino bilíngue ou multilíngue, incluindo as línguas maternas, etc. No parágrafo único. Para o desenvolvimento das atividades pedagógicas, as escolas deverão valer-se da orientação de professores indígenas e de setores específicos do sistema valorizando os materiais coletados por eles, pelos alunos e que vivem efetivamente aos seus objetivos. 
Agora, as diretrizes pedagógicas de Centros Municipais de Educação Escolar Indígena/ CMEEI ${ }^{4}$. Então, desde 2005, quando foi criado o Núcleo de Educação Escolar Indígena-NEEI, está diretamente vinculado à Coordenadoria de Gestão EducacionalDEGE, de início estes CMEEIs eram denominados de Espaços Culturais como Espaços de Educação Indígena (DPEEI), Manaus, 2017, p.62). O conceito de Espaço Cultural:

é um lugar para reuniões de deliberação e das decisões do grupo étnico. Este espaço cultural é reconhecido dentro da Gerencia de Educação Escolar Indígena - SEMED-Manaus, é reconhecido como espaço cultural e cada espaço tem o nome cultural de cada grupo étnico. Além de ser espaço de encontro étnico, mas, a relação da alteridade étnica, expressando cultura, lugar de encontro dos parentes, para os trabalhos de artesanatos, para partilha de alimentos e da retribuição, lugar do ritual de dabucuri (oferta) da expressão da pintura facial, dos discursos em memórias de seus antepassados, um espaço de união e fortalecimento da identidade indígena (Idem, p.63).

Cada comunidade tem seu espaço cultural. Nestes espaços culturais são realizados o fortalecimento dos elementos culturais de seu respectivo grupo. Uma grande conquista das comunidades indígenas de serem reconhecidos pela secretaria municipal de educação, esses espaços culturais têm se tornado como lugar de transmissão de conhecimentos e dos valores culturais de seus respectivos grupos étnicos.

Este lugar cultural tem se tornado espaço da transmissão oral para sistematização pedagógica dos conhecimentos tradicionais, dando sentido do espaço cultural para espaço da educação escolar indígena, com seu modo de pensar, de organizar, de planejar e de executar numa perspectiva sociológica e antropológica.

O espaço cultural é o lugar de ensino-aprendizagem para nova geração citadina, pertencentes às etnias, muitas pessoas de várias etnias vieram para cidade e, muitos deles nasceram neste contexto urbano, fora e longe de suas origens. Muitos deles não viveram o modo de vida dos antepassados. Na cidade, o centro cultural se tornou como lugar de fortalecimento dos conhecimentos patrilinear e matrilinear.

Os filhos que nascem na cidade são ensinados a falar segunda língua e muitos destes fazem empréstimo linguístico da língua portuguesa. A língua materna ficou como língua difícil de aprender a falar pelos filhos.

A educação indígena é objeto da pedagogia para serem elaboradas, sistematizadas com os conhecimentos tradicionais que atendam e respondam aos desafios do contexto social. O espaço cultural é um poço do saber local. O fazer educação de modo sistemático num modo tradicional indígena é um modo de ensino especifico, 0 estudo das línguas, a oralidade, os saberes dos povos e conhecimentos universais, que se interagem na modalidade de ensino (DPEEI, 2017, p.66).

\footnotetext{
${ }^{4}$ Diretrizes pedagógicas da Educação Escolar Indígena do Município de Manaus, 2017, pp.62-69. 
A identidade procede dos saberes tradicionais vinculados à memória coletiva dos povos da Amazônia, à relação com a biodiversidade, com suas formas peculiares de uso e manejo dos recursos naturais, que integram no processo de ensino e aprendizagem dos Centros Municipais de Educação Escolar Indígena e das Escolas Indígenas. Para educação escolar indígena são seus processos pedagógicos e curriculares que promovem as relações de políticas de identidade.

Os princípios de CMEEIs vêm da interculturalidade, bilinguismo/multilinguismo, especificidade, diferenciação e comunitarismo, que são elementos norteadores da educação escolar indígena. Os Centros Municipais de Educação Escolar Indígena atribuem os seguintes princípios e finalidades:

I-O direito de revitalizar e fortalecer suas culturas e língua materna; II-A democratização do acesso e da permanência, da qualidade social da educação e da gestão;

Finalidades:

I-Promover a interlocução entre conhecimentos indígenas e conhecimentos científicos;

II-Fortalecer e consolidar saberes indígenas por meio do diálogo intercultural;

III-Socializar experiências educativas nas comunidades indígenas a partir de seus critérios étnicos em consonância com as diretrizes de bases da Educação Escolar Indígena;

V-Garantir o efetivo e sistemático acesso da comunidade indígena a atividade que promovam o fortalecimento da identidade cultura

O professor de Centro Municipal elabora o projeto pedagógico para ser apreciado e aprovado para ser desenvolvido durante o ano letivo. O projeto pedagógico é indicador de todo processo de participação da comunidade e do ensino-aprendizagem. O professor é pequeno gestor pedagógico que alfabetiza e letraliza na sua língua materna por meio de trabalhos lúdicos, jogos, brincadeiras; rituais, danças; grafismos; desenhos; pinturas; histórias; confecção e montagem de artesanatos e de outros elementos culturais de seu respectivo do grupo étnico.

Neste recorte histórico, contudo, a educação escolar indígena no Município de Manaus tem consonância nas Leis Nacionais da Educação Escolar Indígena para fortalecer a cultura dos povos originários do Brasil. Os povos indígenas sempre mantiveram seus conhecimentos articulados para manter unidade sociológica e antropológica.

\subsection{Procedimento metodológico}

Quanto à metodologia desta pesquisa, esta se deu sob a abordagem qualitativa por meio da pesquisa documental e de campo, no que diz respeito à coleta de dados, 
essa se realizou por meio da pesquisa in loco. Ainda, nesta parte foram empregados os seguintes instrumentos: a observação participante, questionário com perguntas fechadas e entrevistas individuais (Vieira, 2012) semiestruturadas, o registro dos relatos de memória. Neste sentido, o registro dos relatos são histórias verdadeiras, como menciona Eliade (1972), que afirma que os relatos na entrevista narram às experiências pessoais para evidenciar as histórias verdadeiras de vidas. Assim, como estratégia, fez-se uso de questões pontuais para fluir o diálogo na língua do povo indígena tukano, posteriormente foi necessária uma tradução aproximada e equivocada para o português que o pesquisador tomou o cuidado de adaptar em consonância à metodologia empregada com base nas postulações de Marconi; Lakatos (2003).

Para realizar este trabalho, as entrevistas ${ }^{5}$ foram agendadas em datas distintas para não haver constrangimento ou influenciar o seu próprio pensamento entre líder comunitário e a professora bilíngue. A roda de conversa transcorreu na calada da noite, pois assim segundo costume local do rio Negro, o diálogo flui melhor. O método de pesquisa foi ajustado ao costume local das comunidades indígenas de Manaus, embalado por uma roda de conversa com as lideranças e com as professoras bilíngues, falando da educação escolar indígena de centros municipais. Os colaboradores desta pesquisa foram:

Umusipô - Deolinda Freitas, 69 anos de idade, da etnia Desana, fundadora da comunidade e vice-coordenadora de Numiâ Kura da Amarn e artesã.

Umusipô- Joana Montanha, 42 anos de idade, da etnia Desana, professora bilíngue.

Seribi-Justino Melchior Pena, 55 anos de idade, da etnia Tukano, fundador da comunidade Bayaroá e presidente da associação; mestre de danças e pajé.

Duhîgo - Rosiane Lana Pena, 32 anos de idade, da etnia Tukano, artesã, professora bilíngue e técnica em enfermagem.

Para fluir a conversa, foram elaboradas quatro perguntas básicas na língua tukano para liderança e para as professoras bilíngues para falarem sobre educação indígena escolar de centros municipais, como segue abaixo:

1. Ficha da liderança:

1) Nome indígena, nome em português, etnia, idade e função na comunidade.

2) Nesta comunidade, quais foram objetivos de solicitarem para o ensino da língua tukano no centro cultural da comunidade.

3) Todo este processo de ensino, o projeto pedagógico da educação escolar indígena está alcançando na expectativa dos comunitários.

\footnotetext{
${ }^{5}$ De acordo do ABNT são entrevistas, mas, para o povo indígena, a melhor forma de entrevista-lo é uma conversa. Uma roda de conversa que flui melhor sobre conhecimentos tradicionais. 
4) Para Cacique. Como melhorar o ensino da língua materna para o fortalecimento cultural no ensino da língua para os falantes da língua tukano.

Nesta primeira parte da conversa que se deu com as lideranças indígenas, exatamente, para saber os objetivos que tiveram no começo, quando solicitaram a escola indígena, para depois contratar a professora da comunidade indígena urbana para o ensino da língua tukano na rede Municipal de ensino.

Ficha de professor indígena:

1) Nome indígena, nome em português, idade, etnia e função.

2) Para professora. Os objetivos de ensino estão alcançando a meta tão sonhado pela comunidade.

3) Neste centro cultural, quais são dificuldades enfrentadas pela professora ao ensino de tukano.

4) Para você, qual é melhor forma de alcance do ensino da língua materna para o fortalecimento cultural.

Nesta segunda parte da conversa que se deu com as professoras bilíngues, exatamente, para saber os objetivos de cada projeto pedagógico, se há participação da comunidade (lideranças e ancião sábios), a forma de assessoramento pedagógico e quais dificuldades que a professora enfrenta no seu trabalho da comunidade indígena urbana para o funcionamento de educação escolar indígena no Centro Municipal.

Por meio de roda de conversa é verificar a metodologia de ensino das professoras bilíngue nos centros municipais. Enfim, quanto esta metodologia de pesquisa sob a abordagem qualitativa proporcionou para conhecer todo o processo de ensinoaprendizagem da língua materna tukano.

\section{Análise e discussão}

3. 1 Ensino da língua tukano nos Centros Municipais da Educação Escolar Indígena

Nesta seção pretende analisar e discutir as falas das professoras na entrevista de Centros Municipais da Educação Escolar Indígena-CMEEIs. Os dados coletados demonstram de duas comunidades do Alto Rio Negro, Numiâ Kura (AMARN) e da

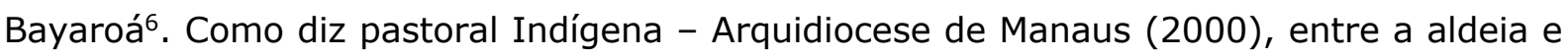
a cidade:

Os bairros da periferia tornaram-se inchados de toda ordem, desde as precárias condições de moradia, à falta de infraestrutura de saneamento básico, elevado índice de criminalidade e violência, falta de assistência adequada à

${ }^{6}$ Cf. No trabalho de Almeida; Santos, Estigmatização e território: Mapeamento situacional dos indígenas em Manaus, 2008, pp.55-56. 
saúde e educação, entre tantos ouros. O mais grave de tudo isso é a falta de perspectiva de quem mora nessas localidades (PIM, 2000, p.3).

O contexto social é dramático para os povos indígenas. Há muitas razões por terem deixados suas aldeias de origens para morar em Manaus. Algumas moças indígenas foram trazidas para trabalhar como empregadas domésticas em residências.

O mais grave de tudo é a falta de perspectiva de quem mora nessas localidades. A cada dia aumenta o número de desempregados e subempregados, mas sobra ainda muita gente que não consegue arranjar trabalho de espécie alguma. É nesse cenário dramático que encontramos milhares de indígenas. A partir dessa situação complexa, como oferecer uma escola indígena. Pensar uma perspectiva que supre de toda forma da violência, agressão e exploração, discriminação e do preconceito, violação dos direitos humanos, agressão físico e moral.

A fala das lideranças traz uma reflexividade pedagógica para dar conta dessa vida sofrida e existem muitas coisas que poderiam solucionar os problemas sociais. Não é uma questão material, porém, aquilo que machuca no interior das pessoas.

Além de ser ofertado uma educação escolar indígena para os citadinos é pensar numa psicopedagogia à educação indígena. A intencionalidade dos pais acaba equivocando pelo desempenho dos alunos indígenas. O saber local dos indígenas deveria dar outro modo de pensar e de ser indígena dentro do contexto urbano. Uma educação indígena que permita as pessoas serem felizes e de ter autoestima.

A intelectualidade de seus saberes tradicionais embasa numa vida boa para uma boa convivência entre seus pares. Uma educação que fale os valores culturais de seu respectivo do grupo étnico. Toda língua tem sua lógica e raciocínio para expressar uma locução adverbial.

Segundo, Dona Deolinda (2019), a assessora pedagógica da Comunidade da Amarn incentivou às mulheres desta associação, para que os filhos das associadas não esquecessem os valores culturais do Alto rio Negro, pois, os elementos culturais que dão sentido à existência para o povo indígena. Há muito tempo, os nossos antepassados ou anciãos das aldeias, nas margens, lagos, rios e nas cabeceiras dos rios, já se tinham esta preocupação para que os filhos ou netos não esquecessem dos valores culturais de seu respectivo grupo étnico. A cidade como local de afirmação dos direitos indígenas.

Agora, já na cidade são as lideranças que se preocupam para manter a cultura viva. A solicitação de escolas nas respectivas comunidades indígenas. O Senhor Justino quanto a Dona Deolinda lembrou os objetivos de ter a escola indígena para o fortalecimento cultural. Naquele tempo, se chamava de Centros Culturais, mas, atualmente, denomina-se de Centros Municipais Educação Escolar Indígena (CMEEIs). 
Essa escola indígena para as famílias deslocadas aqui na cidade de Manaus. Como eles disseram muitas famílias vieram para a cidade em busca da melhoria de vida. No livro de Bernal (2009) aparecem muitas famílias que vieram de várias regiões do Estado do Amazonas, caso aqui do Rio Negro:

a maioria dos índios que vivem na cidade de Manaus vem da região do Alto Rio Negro ou desce das tribos que povoavam antigamente essa região. Entre eles: Tukano, Wanana, Desana, Tariano, Piratapuya, Tuyuka, Baré e Baniwa. A imensa maioria dentre eles passa despercebida na circulação humana de uma cidade constituída inteiramente de imigrantes (Bernal, 2009, p.59).

Primeiramente, as famílias indígenas deslocadas pertencem ao Município de São Gabriel da Cachoeira, Estado do Amazonas, vieram em busca da melhoria de vida na cidade de Manaus. Por aqui, trabalharam na Fazendo São Pedro, outras como diaristas, domésticas, etc.

A maioria das vezes foram explorados pelos patrões, sem encargos sociais, discriminados nos locais de serviços. Nos relatos percebeu-se que muitos tiveram os traumas psicológicos.

Em segundo lugar, essas famílias indígenas estavam sem perspectivismo de vida na cidade. É muita dificuldade de conseguir outro trabalho digno. No caso da Numiâ Kura, uma antropóloga foi muito importante na conscientização de organização social para conseguir criar autoestima das pessoas. A princípio do trabalho foi artesanato, saúde e educação. A comunidade Bayaroá surgiu com objetivos semelhantes, mas, com os objetivos de apresentação cultural e venda de artesanato para os sustentos das famílias. Atualmente, as duas comunidades trabalham fortemente com a educação indígena e artesanato. Até algumas pessoas não conseguiram superar a questão de desemprego. Vendo por outro lado, o fator social, foi muito importante para organização das famílias indígenas, a cidade como local de afirmação dos direitos indígenas. Isso nos remete no próprio artigo 231 da constituição brasileira.

A Associação das Mulheres do Alto Rio Negro em Manaus - AMARN, surgiu e foi criada no 1984 pela iniciativa de uma antropóloga norte americana Janet Chernela. A comunidade Bayaroá surgiu no ano 2003 e só foi juridicamente regularizado no 2007.

Em terceiro momento, as associações, comunidades, grupos de famílias organizadas indígenas começam a pensar de forma articulada e planejada junto com os demais órgãos competentes, para que município de Manaus oferte a educação escola indígena. A escola indígena tem como objetivo a conquista da autonomia sócioeconômico-cultural de cada povo, 
contextualizada na recuperação de sua memória histórica, na reafirmação de sua identidade étnica, no estudo e valorização da própria língua e da própria ciência, sintetizadas em seus etnoconhecimentos, bem como no acesso às informações e aos conhecimentos científicos e técnicos da sociedade majoritária e das demais sociedades indígenas e não indígenas (Art. 78, I e II).

As próprias sedes de associações indígenas ou as próprias residências funcionam como Centros Municipais da educação escolar indígena. No entanto, no perímetro urbano, a prefeitura de Manaus não constrói escolas indígenas. Essas sedes indígenas não têm estrutura ideal para funcionamento de escola. Os espaços que as associações dispõem são espaços multifuncionais, de reuniões, assembleias, missas católicas, encontros dos movimentos indígenas, oficinas, palestras, seminários, para realizações dos rituais tradicionais, confecção e montagens de artesanatos, festas civis e religiosas. $\mathrm{Na}$ proximidade de Centros municipais não tem rios, matas ou áreas verdes para desenvolver o projeto pedagógico.

É muito evidente, na fala de Dona Deolinda, todos dias, os pais das crianças enfrentam os males da cidade. Os pais acordam cedo e vão de ônibus nos seus afazeres domésticos, como diaristas, outros como pedreiro, servente do pedreiro, etc. e vejamos o cotidiano das famílias.

Aqui na cidade, nem tempo para conversar com os filhos a gente tem. Na aldeia, o tuxaua reunia com a gente e ensinava muitas coisas boas da nossa vida, da nossa cultura. Os nossos parentes mais velhos ensinam toda a nossa história só falando, sem ter que escrever nada. São gentes de muita sabedoria. Mas na cidade isso já era! (PIM, 2000, p.30).

Por isso, as lideranças, os anciãos sábios e as professoras bilíngues tomaram consciência a importância da transmissão oral dos conhecimentos tradicionais para educação escolar indígena nas comunidades indígenas. A tradição é entendida por Eric: Tradição é um conjunto de práticas normalmente reguladas por regras tácitas ou abertamente aceitas. Tais práticas, de natureza concreta ou simbólicas, visam inculcar certos valores e normas de comportamento através da repetição (Hobsbawsm, 1984, p.9).

$\mathrm{Na}$ transcrição das entrevistas foi percebido que, para funcionar o espaço de ensino da língua tukano, a cultura dos antepassados. Uma escola indígena para que os filhos que nascem na cidade não se esqueceram os valores, as riquezas culturais dos patrilineares e das matrilineares, mesmo longe da aldeia, fora de suas origens, mas, para lembrar o modo de vida dos antepassados morando na cidade de Manaus. E, por alguns 
anos, estes conhecimentos tradicionais ficaram abandonados e esquecidos por conta do preconceito e da discriminação.

A língua como processo de afirmação da identidade do professor. Segundo, Altaci (2011), na sua dissertação de mestrado traz a importância de aprender e valor que se tem, "a língua vai nos possibilitar para visualizar as especificidades, as peculiaridades de cada povo com o intuito de afirmar e reafirmar a identidade étnica" (Rubim, 2011, p.120).

A educação escolar indígena no Município de Manaus é um avanço significativo, apesar da precariedade, a irregularidade de funcionamento de Centros Municipais. E já são quase 12 anos de funcionamento de Educação Escolar Indígena. O sonho de todos de Centros Municipais de serem regularizados pelo município de Manaus.

Todas as duas professoras bilíngues manifestaram suas insatisfações com o assessoramento pedagógico. A atribuição para assessora pedagógica:

- Conhecer o contexto social da comunidade

- Participar as atividades de centros culturais

- Ter noções básicas da língua ensinada

Ao longo do curso de especialização, volto aquela questão que se dizia que o gestor escolar deve conhecer o contexto social da escola. Isto significa que o projeto pedagógico deve ser uma resposta ao problema social. Aquilo que Dona Deolinda lembrava na sua fala. Algumas crianças, quando se tornam adolescentes criam vergonha (Deolinda, 2019).

Diante desse fator social, pensar, o projeto de fortalecimento de longo prazo. Atualmente, o projeto de fortalecimento cultural é de imediato, parece-me tem certos limites pedagógicos. Pensando nas crianças que nasceram já aqui na cidade, o projeto pedagógico não deveria ser só para saber da escrita. O ensino da língua tukano pensar em três níveis de processo aprendizagem:

1. Alfabetizar-Letrar na língua materna com gestão participativa;

2. Utilizar os materiais didáticos, $e$

3. Trabalhar na área da psicopedagogia.

E, aí assim, estaremos ensinando, transmitindo os valores culturais de seu respectivo grupo étnico. Mostrar para aluno indígena falar sua língua materna que tem capacidade de domínio das línguas. Falar a língua materna é valorizar sua própria língua dos seus antepassados. Para isto acontecer é necessário de ser trabalhada, a questão da psicopedagogia. Todo indígena deveria falar sua língua materna. Quando não sabe falar a língua materna é uma vergonha. Falar a língua materna não diminui o seu modo de ser indígena, mas, fortalece diante da discriminação e de preconceito. 
Apesar de esforço pedagógico continuaremos de ter o ensino da língua tukano que não fala e não se pode ficar só lamentando de que aluno não fala de tukano, apenas só ouve. Como a nova geração se encontra na cidade, óbvio, segundo Maia (2006) a importância entre oral e o escrito. A fala é de base auditiva, enquanto que a escrita é de base visual. É necessário levar em consideração, as falas de duas professoras bilíngues, em relação da sensibilidade pedagógica. As professoras acreditam muito que fossem os próprios assessores pedagógicos indígenas. Para elas, este proporcionaria melhor na execução do projeto de ensino, pois ele sabe e conhece o aspecto cultural de seu povo.

Outra possibilidade é de ter próprios indígenas que têm a formação acadêmica como doutorado para assessoramento pedagógico; segundo as professoras, este professor indígena deveria de ter mais diálogo e da sensibilidade pedagógica. Segundo Melià (1979), o índio já tem um sistema de educação próprio, e a educação que a sociedade nacional tem dado para estas comunidades deveria lhe ser complementar e não substituição.

O próprio assessor pedagógico tornaria êmico ao ensino da língua materna tukano. O dia de assessoramento pedagógico é um momento de uma troca de experiência do projeto. O assessor não-indígena não houve as falas das professoras e criar numa situação constrangedora. As professoras preferem ficar caladas e seguir as orientações de quem dispõe em ajudá-lo.

Pensar no assessor pedagógico de Centro Municipal para construir a gestão participativa, como afirma no decreto municipal. Às vezes, o assessor pedagógico da Gerencia de educação escolar indígena acaba influenciando a política da Secretaria Municipal de Educação. Todo ano tem metas e objetivos, mas esquece que aquele centro cultural sua meta e seus objetivos a serem alcançados, no trabalho em conjunto.

No momento de assessoramento pedagógico não poderia haver constrangimento, não se pode deixar a professora de mãos cruzadas. As professoras sabem e conhecem valores culturais. Só uma questão de sensibilidade do assessoramento pedagógico. $\mathrm{Na}$ tese de doutorado do pesquisador Grupioni (2008), a qual ele menciona a fala do professor tukano do Alto rio Negro:

Nossas escolas ainda não são indígenas. São reconhecidas pelo município, pelo estado, mas falta discutir calendário, currículo, regimento, materiais bilíngues. Elas são reconhecidas, mas não como indígenas. (...). A escola indígena que queremos tem que quer ser da mesma forma, tem que estar dentro da nossa cultura. A escola que temos não dá para o nosso futuro, porque ela não tem projeto futuro. A escola tem que estar voltada para nossa cultura, para nossa comunidade, queremos formar pessoas que continuem sendo índios.

Sebastião Duarte Tukano, 1996. 
O professor de centro municipal é um êmico de sua própria língua falada, sabe e conhece bem a cultura de seu povo. Mas, o modo de organização social indígena já é uma gestão participativa e porque não pensar melhor numa forma bem planejada, articulada e de longo prazo. Por fim, o Centros Culturais são lugar de ensinoaprendizagem para o fortalecimento cultural. A educação escolar indígena é uma forma para manter e para não esquecer os valores e riquezas culturais na cidade de Manaus.

\section{Resultado esperado}

Ao averiguar minuciosamente os dados obtidos, estes demonstram que, o ensino da língua materna de Centros Municipais de Educação Escolar Indígena nas sedes das comunidades indígenas é um avanço muito positivo no Município de Manaus. A transmissão dos conhecimentos tradicionais é feita por meio de projeto pedagógico. A educação indígena é para valorizar os elementos culturais de seu respectivo grupo étnico, mesmo estando longe de suas origens. Porém, os centros municipais não são regularizados pelo Município de Manaus. Os respectivos centros não possuem uma estrutura predial. O projeto pedagógico de ensino da língua materna é ineficiente, pois, há uma necessidade do apoio na área de psicopedagogia, diante do preconceito e discriminação. Quando chegam certa idade alguns alunos têm vergonha de sua identidade indígena no meio da sociedade. Em geral, os alunos destes centros são simplesmente ouvintes e não falam nada. Isso dá uma margem muito negativa para o futuro dos povos indígenas que será uma sociedade moderna, apenas de ouvintes.

\section{Considerações finais}

O ensino da língua tukano que não fala é um fator social das famílias citadinas. Estes Centros têm o rosto indígena, tem o nome (Buu Miri Wií e Bayaroá) do Grupo Tukano Oriental, noroeste amazônico, Estado do Amazonas, residente na cidade de Manaus.

Estes espaços de ensinos são espaços culturais para o fortalecimento cultural. A cidade como local de afirmação da identidade étnica. Todos estes espaços de ensinoaprendizagem no município de Manaus funcionam em locais cedidos pelas comunidades indígenas, são espaços coletivos, espaços para alfabetizar-letrar a sua própria língua tukano.

Todo processo do ensino de educação escolar indígena é para os alunos indígenas, para família, em parceria com Secretaria Municipal de Educação/SEMED, com total responsabilidade de contratar o professor para o ensino de bilíngue tendo a participação 
imprescindível do ancião, a biblioteca viva, o detentor dos conhecimentos tradicionais e a disponibilidade de assessoramento pedagógico da Gerência de Educação Escolar Indígena GEEI/SEMED/Manaus.

Agora, apesar de todo esforço, do poder público municipal, das lideranças e das instituições públicas e privadas, os alunos indígenas destes Centros Municipais são simplesmente ouvintes da língua tukano, pois, são os filhos ou netos dos falantes de sua respectiva língua. Este é desafio para a professora bilíngue, para secretaria municipal de educação e para as lideranças indígenas. É, neste sentido, que ensino da língua tukano que não fala e isso que se torna evidente, e, se não fala, como saberá para escrita. A oralidade é mecanismo para escrita para haver uma comunicação e o relacionamento simétrico.

Todo este trabalho é o resultado da roda de conversa com as professoras e com as lideranças indígenas destas comunidades urbanas. Chegou-se uma conclusão aproximada ou equivocada para pensar, discutir, planejar e orçar, a partir do contexto social indígena do saber local para solucionar os problemas das comunidades e das famílias. O modelo de ensino para o fortalecimento cultural não tem eficiência de ensino. Os Centros Municipais, sobretudo, são espaços sociais e coletivos para uma boa convivência para haver comunicação social.

Por fim, o ensino da língua materna não fala e não se pode limitar somente no projeto pedagógico de ensino. É preciso pensar e repensar, para que o aluno chegue a falar sua própria língua e muitos indígenas não passaram dita escola indígena. Ou terá que morder a sua própria língua para poder falar a língua tukano e, assim, haverá diálogo para fluir o pensamento de ser indígena sendo emico de sua língua materna.

\section{Referências bibliográficas}

ALMEIDA, Alfredo W; DOS SANTOS, Glademir Sales. Estigmatização e Territorio. Mapeamento situacional dos indígenas em Manaus, 2008.

Artigo 231 da Constituição da República Federativa do Brasil de 1988.

Artigo 78 da Lei de Diretrizes e Bases da Educação Nacional no 9.394/96

Artigo 79 da Lei de Diretrizes e Bases da Educação Nacional no 9.394/96

Artigo 23 da Lei de Diretrizes e Bases da Educação Nacional no 9.394/96

BERNAL, Roberto J. Índios Urbanos. Processo de reconformação das Identidades Étnicas Indígenas em Manaus, EDUA, Faculdade Dom Bosco, Manaus/Am, 2008.

Decreto no 1.394, de novembro de 2011. Cria escolas indígenas e o reconhecimento da categoria de professores indígenas no sistema de Ensino Municipal no âmbito do município de Manaus. Diário Oficial do município de Manaus, 30/11/2011. Manaus, 2011.

Diretrizes Pedagógicas da Educação Escolar Indígena do Município de Manaus, Manaus, 2017.

Diretrizes para a Política Nacional de Educação Escolar Indígena, Brasília: MEC/SEF; Comite Nacional de Educação Escolar Indígena, 1994.

ELIADE, Mircea. Mito e realidade. Editora Perspectiva S. A, São Paulo, 1972. 
GRUPIONI, L. Donisete B. Olhar longe, porque o futuro é longe. Cultura, escola e professores indígenas no Brasil, São Paulo, 2008.

HOBSBAWN, Eric \& RANGER, Terence (Orgs.) A invenção das tradições. - Rio de Janeiro: Paz e Terra, 1984, pp.9-23.

Lei de Diretrizes e Base da Educação Nacional (LDB), 1996.

MAIA, Marcus. Manual de linguística: subsídios para a formação de professores indígenas na área de linguagem. Brasília: Ministério da Educação, Secretaria de Educação Continuada, Alfabetização e Diversidade; LACED/Museu Nacional, 2006.

MARCONI, M. de Andrade; LAKATOS, Eva M. Fundamentos de metodologia científica. São Paulo Editora Atlas S. A- 2003

MELIÀ, Bartomeu. Educação indígena e alfabetização. Edições Loyola. São Paulo, 1979.

Referencial Curricular Nacional para as Escolas Indígenas RCNEI, Brasília: MEC/SEF, 2005, p. 535

Parecer 14 do Conselho Nacional da Educação/PNE - Diretrizes Nacionais para o funcionamento da Escolas Indígenas, 1999.

Pastoral Indigenista - Arquidiocese de Manaus. Entre a aldeia e a cidade, ManausAmazonas, 2000.

Plano nacional de Educação (PNE) Lei no 10.172/2001.

Resolução 03 do Conselho Nacional de Educação/PNE - Diretrizes Curriculares Nacionais de Educação Escolar Indígena, 1999.

RUBIM, Altaci C. Identidade dos professores indígenas e professores territorialização/Manaus-Am, Dissertação de Mestrado, 2011.

SANTOS, Jonise N. Educação Escolar Indígena no município de Manaus (20052011). Dissertação (mestrado) - Universidade Federal do Amazonas. Manaus, 2011.

VIEIRA, J. Guilherme Silva. Metodologia de Pesquisa Cientifica na Prática. PósGraduação. Módulo básico, FAEL, Paraná, 2012.

MARFAN, Marilda A (Org.). Congresso Brasileiro de qualidade na educação: Formação de professores. Educação Escolar Indígena. Volume 4, Brasília, 2002; Painel 5 Educação Escolar Indígena: Luis Donizete Grupioni: Do nacional ao local, do federal ao estadual: as leis e a Educação Escolar Indígena. 